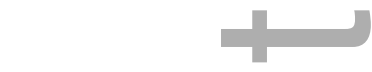 \\ DR TRACEY SHEA (Orcid ID : 0000-0002-0177-349X)
}

Article type : Original Manuscript

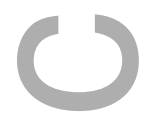

\section{Running heading:}

Work-Related Stressors and Employee Health

Title:

Effects of Work-Related Stressors and Mindfulness on Mental and Physical Health Among Australian Nurses and Healthcare Workers

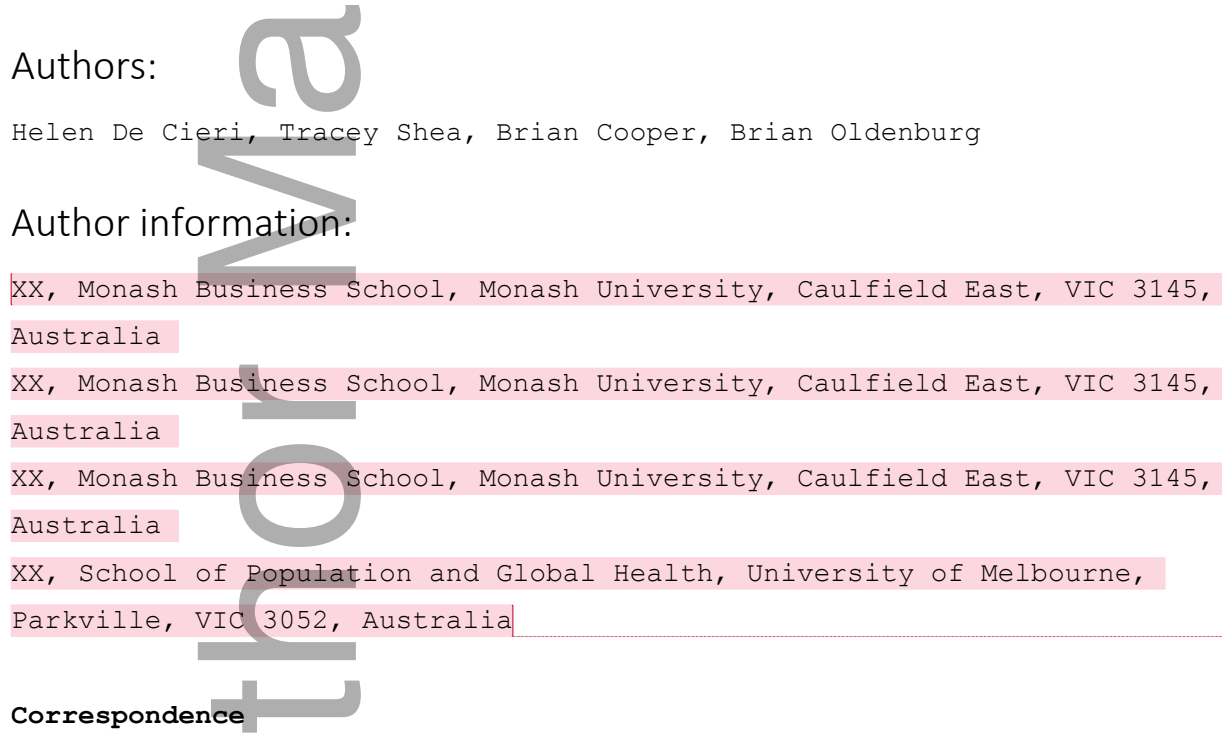

Dr. Tracey Shea, Monash Business School, Monash University, 900 Dandenong Road, Caulfield East, VIC 3145, Australia. E-mail: tracey.shea@monash.edu

This is the author manuscript accepted for publication and has undergone full peer review but has not been through the copyediting, typesetting, pagination and proofreading process, which may lead to differences between this version and the Version of Record. Please cite this article as doi: 10.1111/INU.12502

This article is protected by copyright. All rights reserved 


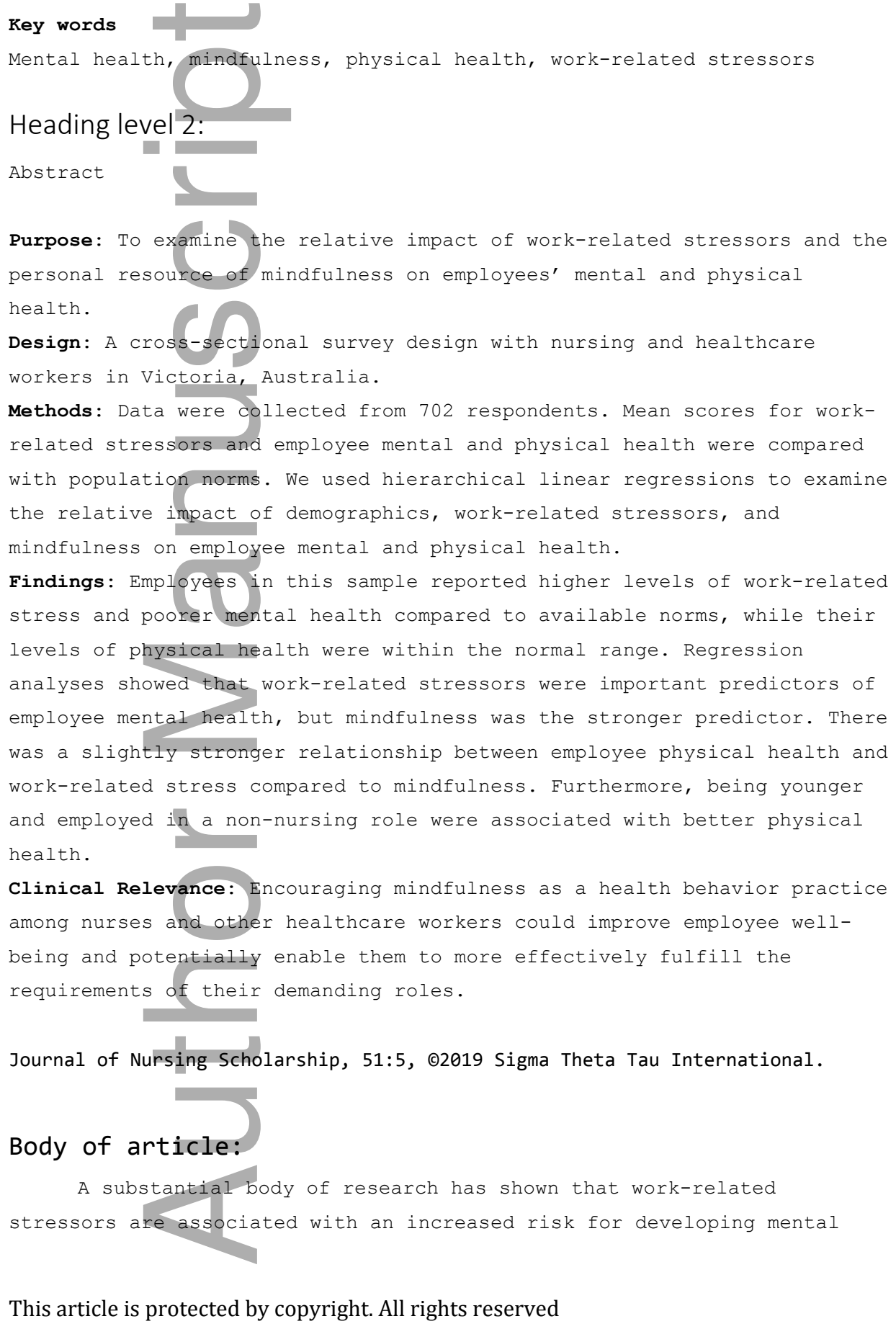

Findings: Employees in this sample reported higher levels of work-related stress and poorer mental health compared to available norms, while their levels of physical health were within the normal range. Regression analyses showed that work-related stressors were important predictors of employee mental health, but mindfulness was the stronger predictor. There was a slightly stronger relationship between employee physical health and work-related stress compared to mindfulness. Furthermore, being younger and employed in a non-nursing role were associated with better physical health.

Clinical Relevance: Encouraging mindfulness as a health behavior practice among nurses and other healthcare workers could improve employee wellbeing and potentially enable them to more effectively fulfill the requirements of their demanding roles.

Journal of Nursing Scholarship, 51:5, @2019 Sigma Theta Tau International. Body of article:
A substantial body of research has shown that work-related
stressors are associated with an increased risk for developing mental This article is protected by copyright. All rights reserved 
health problems such as anxiety and depression (Bartram, Yadegarfar, \& Baldwin, 2009) and physical health conditions such as coronary heart disease (Donovan, Doody, \& Lyons, 2013). The impact of work-related stress on mental and physical health is particularly salient for nurses and other healthcare workers, who have been found to face exposure to a wide range of work-related stressors, including emotional labor (Karimi, Leggat, Donohue, Farrell, \& Couper, 2014; Kinman \& Leggetter, 2016), high workload and job demands (McVicar, 2016), and occupational violence (Shea, Sheehan, Donohue, Cooper, \& De Cieri, 2017). Managing work-related stress in these workers is important given the implications for the health and well-being of healthcare workers (Marcatto et al., 2016), their workplaces in terms of job performance (Chu, 2017), and society such as the quality of patient care (Cho \& Han, 2018) and worker compensation costs (Safe Work Australia, 2018a). In Australia, workers in the healthcare and welfare industry are responsible for the highest proportion of compensation claims for work-related injury and illness each year (Safe Work Australia, 2018b). Further, in Australia for the 5year period 2010-2011 to 2014-2015, compensation claims for work-related mental health conditions cost approximately AUD543 million a year, and most compensation claims for a mental health condition were associated with work-related stress (Safe Work Australia, 2018a).

The Job Demands-Resources (JD-R) theory (Demerouti, Bakker, Nachreiner, \& Schaufeli, 2001; van Woerkom, Bakker, \& Nishii, 2016) distinguishes between demands and resources that may arise either from the job context or from personal circumstances. Work-related stressors, such as having too little time to complete one's work or lacking control over the timing and methods of work, include job demands that require employees to expend additional effort that over time can cause exhaustion and lead to negative outcomes (Mackay, Palferman, \& Buckley, 2015). On the other hand, resources help employees to cope with demanding situations; relationships between job-related demands and job-related resources are well-established (van den Tooren \& de Jong, 2014). Schaufeli and Taris (2014) extended the JD-R theory to include personal resources outside the work domain that could mitigate the negative effects of job demands. While healthy lifestyle practices have been reported to improve the quality of nursing care (Cho \& Han, 2018),

\section{This article is protected by copyright. All rights reserved}


relatively little is known about the role of personal resources and their potential to help nurses and healthcare workers deal with job demands (cf. Schmidt \& Diestel, 2013).

We focus on the personal resource of mindfulness, as several studies have shown that mindfulness can improve employee well-being, with preliminary evidence showing benefits for nursing employees (Foureur, Besley, Burton, Yu, \& Crisp, 2013; Guillaumie, Boiral, \& Champagne, 2017) and is associated with a reduction in negative outcomes such as emotional exhaustion (Huhlsheger, Alberts, Feinholdt, \& Lang, 2013). Mindfulness, which has been defined as "the awareness that emerges through paying attention on purpose, in the present moment, and nonjudgmentally to the unfolding of experience moment by moment" (Kabat-Zinn, 2003, p. 145), has been shown to have protective effects for workers where those with low levels of mindfulness would experience increased anxiety after being exposed to individual work-related stressors (e.g., conflicts with other staff) compared to those with higher levels of mindfulness (Westphal et al., 2015). Grover, Teo, Pick, and Roche (2016) found that mindfulness can influence an individual's perception of job demands. Mindfulness has also been shown to facilitate improved relationships at work (Glomb \& Liao, 2003; Good et al., 2015; Reb, Narayanan, \& Chaturvedi, 2014). However, a review of the mindfulness literature by Good et al. (2015) indicates that research is still in an early stage with respect to investigating the relationship between mindfulness and work-related stressors.

This study seeks to examine how work-related stressors along with mindfulness are associated with mental and physical health for nurses and healthcare workers. While we expect both work-related stressors and mindfulness to predict employee health, in this study we propose to examine the effect of mindfulness on employee mental and physical health, after taking into account the impact of work-related stressors. Our hypotheses are:

Inset list:

H1: After adjusting for work-related stressors, mindfulness will have a positive relationship with employee mental health. H2: After adjusting for work-related stressors, mindfulness will have a positive relationship with employee physical health.

\section{This article is protected by copyright. All rights reserved}




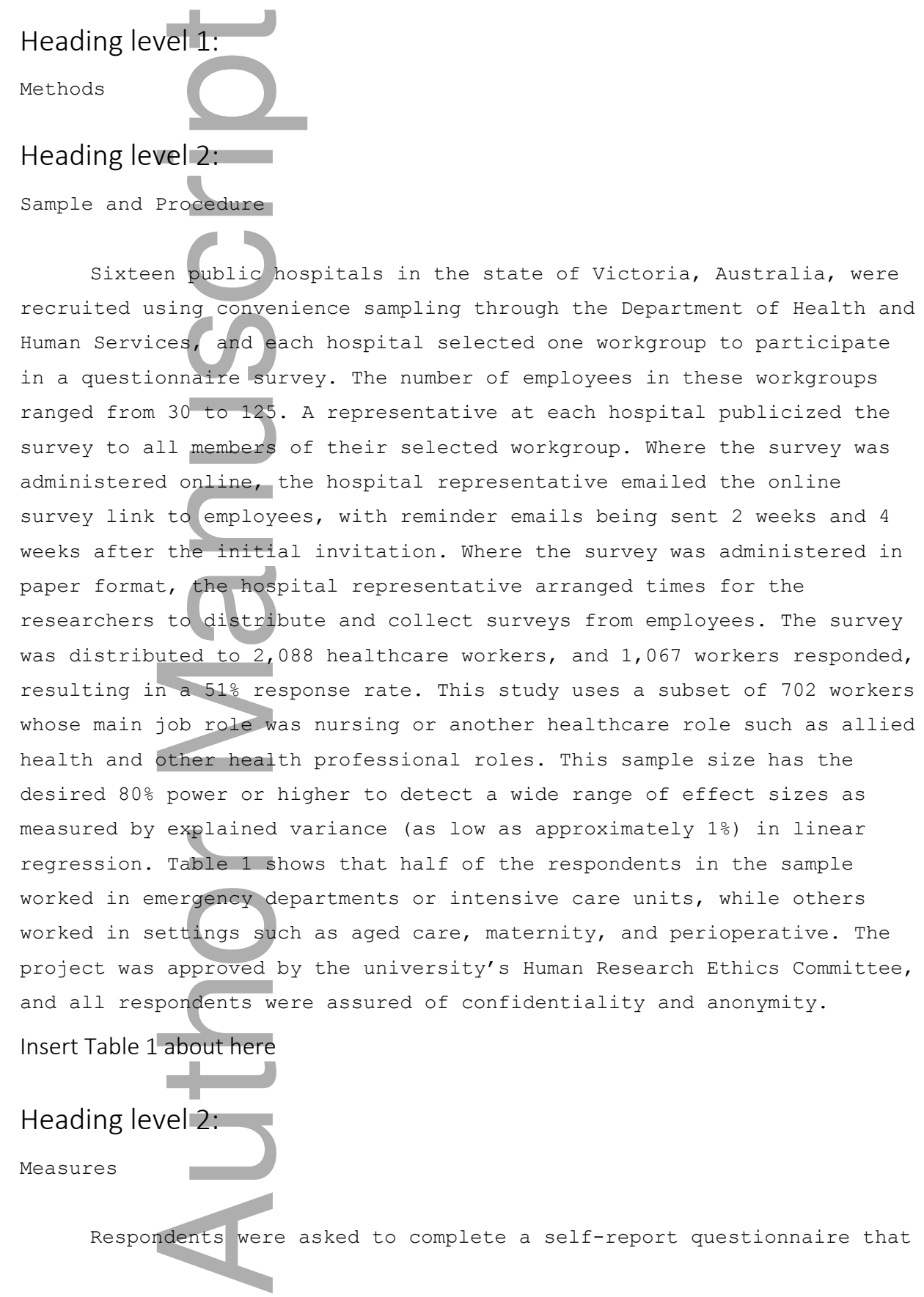

This article is protected by copyright. All rights reserved 
measured work-related stressors, mindfulness, mental and physical health, and demographic variables.

\section{Heading level 3 :}

Work-related stressors. We measured work-related stressors using the 35-item Health and Safety Executive Management Standards Indicator Tool (HSE-MSIT; Cousins et al., 2004; Edwards, Webster, Van Laar, \& Easton, 2008). The HSE-MSIT has been tested extensively in several countries and has been shown to be a valid and reliable measure of workrelated stressors. Most notably, its validity and reliability has been established through its initial piloting and development by cousins et al. (2004) and benchmarking on a sample of 26,382 employees in 39 organizations in the United Kingdom (Edwards et al., 2008). The HSE-MSIT represents "states to be achieved" or good management practices such that low scores represent a need for improvement. The seven subscales are: demands (8 items: e.g., time pressures at work); control (6 items: e.g., the amount of say in the way work is done); manager support (5 items: e.g., encouragement and support); peer support (4 items: e.g., support and respect from peers); relationships (4 items: e.g., avoidance of conflict and workplace aggression); role (5 items: e.g., clarity around job role); and change (3 items: e.g., communication of organizational change). The items are rated on either a 5-point Likert scale $(1=$ strongly disagree to $5=$ strongly agree) or a 5-point frequency scale (1 = never, 2 = seldom, 3 = sometimes, 4 = often, 5 = always), which are averaged so that scores for all subscales range from 1 to 5 . As recommended by Cousins et al. (2004) we reverse scored the demands and relationship subscales so that high scores reflect more positive outcomes consistent with the other five subscales.

The mean score for each subscale can be compared with norms developed in the United Kingdom (see Edwards \& Webster, 2012; Edwards et al., 2008; Health and Safety Executive, n.d.) by classifying the score into one of four categories that are associated with recommendations depending on the score. The categories are: average scores that are below the 20 th percentile (urgent action is required); between the 20 th and 50 th percentiles (clear need of improvement); between the 50 th and 80 th percentiles (better than average but still needs improvement); and above

\section{This article is protected by copyright. All rights reserved}


the 80th percentile (doing very well).

\section{Heading level 3 :}

Mindfulness. We used the Cognitive and Affective Mindfulness ScaleRevised (CAMS-R; Feldman, Hayes, Kumar, Greeson, \& Laurenceau, 2007) to measure mindfulness. This short scale was validated and shown to have good psychometric properties with respect to convergent and discriminant validity and reliability (Feldman et al., 2007). The CAMS-R contains 12 items that are rated on a 4-point frequency scale ( 1 = rarely, not at all, 2 = sometimes, 3 = often, 4 =almost always), which are averaged so that scores range from 1 to 4, with higher scores indicating greater mindfulness.

\section{Heading level 3}

Employee mental and physical health. Employee mental and physical health were assessed using the Short-Form 12v2 (SF-12; Maruish, 2012), a 12-item measure that elicits respondents' views of their general mental and physical health status and their capacity to do their usual activities in daily life. The SF-12 is derived from the SF-36, which has been validated in several countries, including Australia (e.g., Avery, Dal Grande, \& Taylor, 2004). The SF-12 is a multipurpose (i.e., generic rather than disease-specific), short-form survey that summarizes general health status across eight dimensions: physical functioning, role limitations due to physical functioning, bodily pain, general health, vitality, social functioning, role limitations due to emotional problems, and mental health (Ware, Kosinski, \& Keller, 1996). The SF-12 is a widely used measure of health-related status and disability and has been used in a range of settings for both clinical (e.g., Le Grande, Tucker, Bunker, \& Jackson, 2019) and working (e.g., Perry et al., 2017) populations. We generated the two composite scores for mental health (five items) and physical health (seven items). The SF-12 composite scores range from 0 to 100, with higher scores indicating better functional outcomes. Australian population mean scores for the SF-12 are at 50 with a standard deviation of 10 for the physical and mental health components (Australian Bureau of Statistics, 1997). Scores within a 0.3 standard deviation of the mean (range 47 to 53) are considered to be within a normal range, while mean

\section{This article is protected by copyright. All rights reserved}




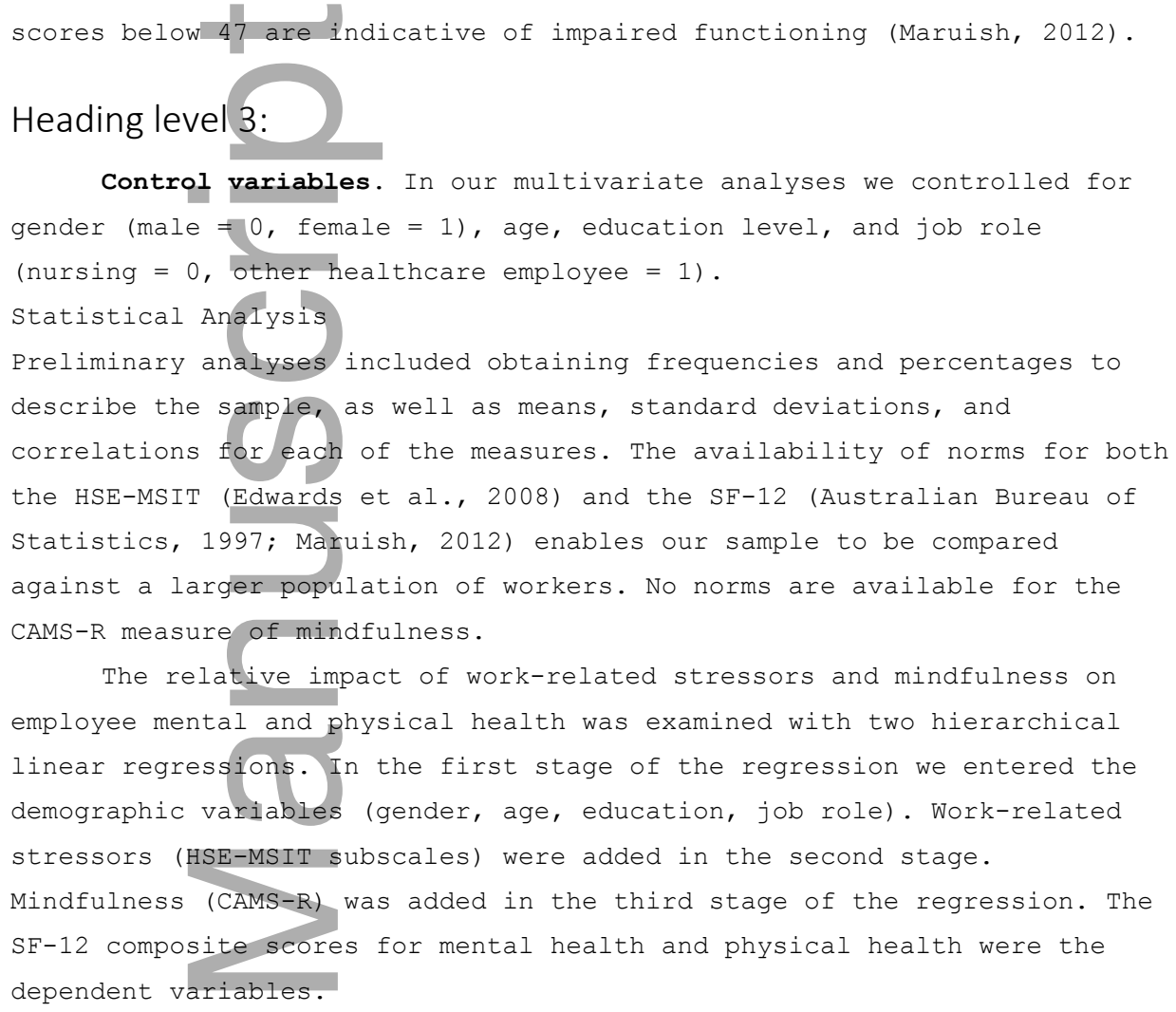

Heading level 1:

Results

Table 1 shows that most respondents were female, 36 years of age or older, educated to a tertiary level, and employed in a nursing role. Respondents were anonymous so could not directly be compared with nonrespondents, but the distribution of nurses and other healthcare workers in this study is consistent with the healthcare workforce in Australia, where nurses and midwives are the largest occupational group in the Australian healthcare workforce (Australian Institute of Health and Welfare, 2018).

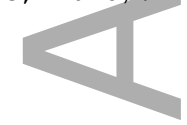

This article is protected by copyright. All rights reserved 


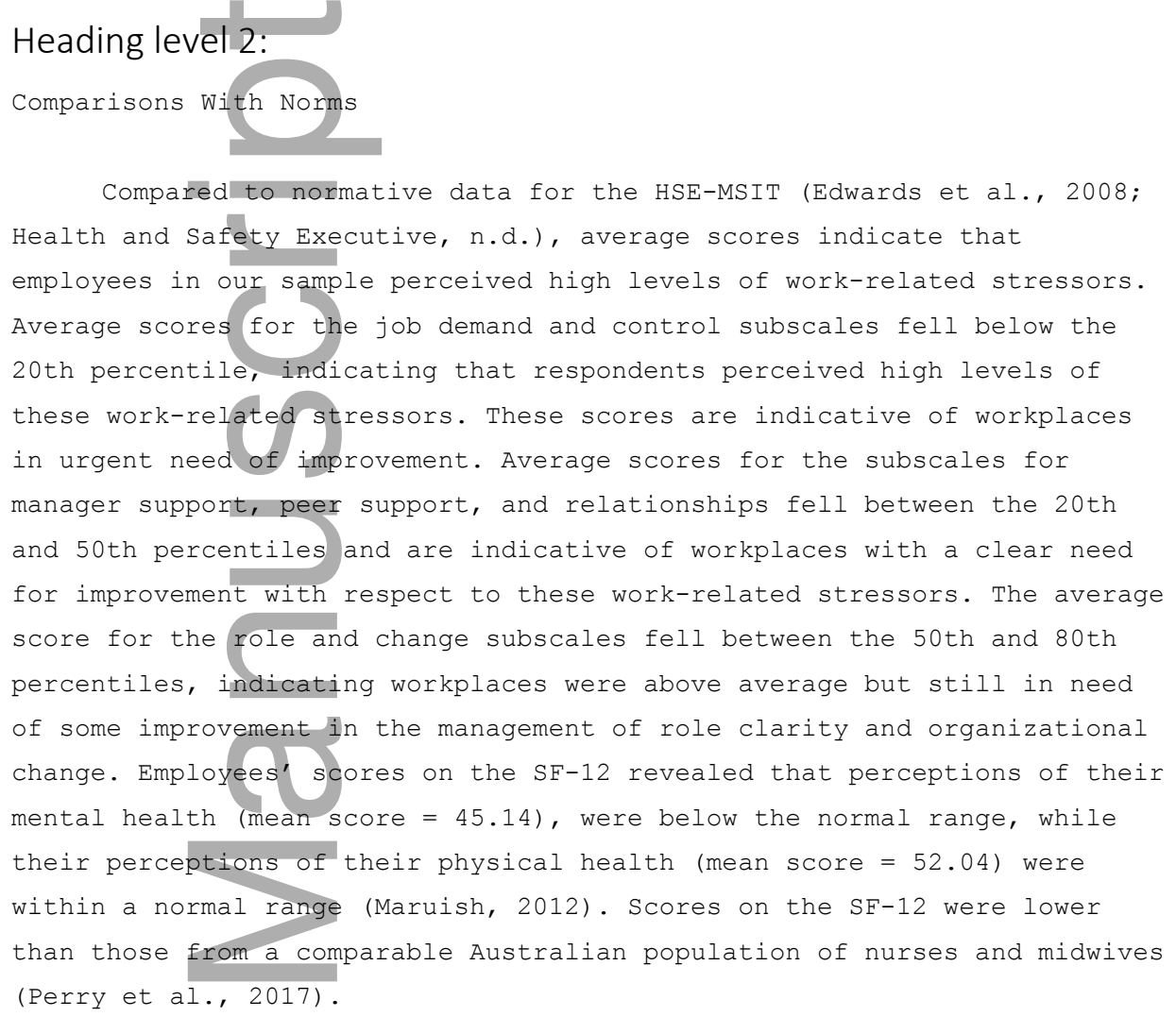

This article is protected by copyright. All rights reserved 
statistically significant positive correlations between mindfulness and both mental health and physical health. Employees with higher levels of mindfulness tended to have better mental and physical health.

Insert Table 2 about here

Heading level 2

Hierarchical Linear Regression Analyses[JC1]

\section{Heading level 3 :}

Mental health. In the first stage of the regression, gender, age, education, and job role explained 3\% of the variance in employee mental health $[F(4,611)=5.01, p<.001]$. Age was the only significant

predictor. In the second stage, the demographic variables and the seven work-related stressors explained 25\% of the variance in mental health $[F(11,604)=17.89, p<.001]$, and the change in $R^{2}$ from the first stage was significant $[F(7,604)=24.49, p<.001]$. Age, job demands, job control, peer support, and relationships were significant predictors of employee mental health.

In the final model, with the addition of mindfulness, the model explained 41\% of the variance in employee mental health $[F(12,603)=$ 35.08, $p<.001]$, and the change in $R^{2}$ from the second stage was significant $[F(1,603)=169.33, p<.001]$. A higher level of mindfulness, fewer job demands (e.g., fewer time pressures), and being older were significantly associated with better mental health. Mindfulness accounted for 29\% of the variance in mental health. These results support Hypothesis 1. The unstandardized regression coefficient shows that for each unit increase in mindfulness, the mental health score is predicted to increase by 10.0 , representing a 10\% increase or 1 standard deviation. Heading level 3:

Physical health. In the first stage of the regression, gender, age, education, and job role explained 6\% of the variance in employee physical health $F(4,611)=10.06, p<.001]$. Age and job role were the only significant predictors. In the second stage, the demographic variables and work-related stressors explained $8 \%$ of the variance in employee

This article is protected by copyright. All rights reserved 
physical health $[F(11,604)=4.85, p<.001]$, although the change in $R^{2}$ was not statistically significant $[F(7,604)=1.82, p=.081]$. In the final model, with the addition of mindfulness, the change in $R^{2}$ was statistically significant $[F(1,603)=6.62, p=.010]$, with the overall model explaining $9 \%$ of the variance in employee physical health $[F(12,603)=5.04, p<.001]$. Better relationships at work and a higher level of mindfulness were significantly associated with better physical health, which provides support for Hypothesis 2. Additionally, being younger and employed in a non-nursing healthcare role were significantly associated with better physical health.

\section{Heading level 3:}

Posthoc analysis. We conducted a post-hoc analysis to include interaction terms for work-related stressors and mindfulness to see the theoretical possibility that mindfulness protects or buffers the negative effects of work-related stressors. We conducted moderated regressions for both mental health and physical health as dependent variables, and the demographic variables, work-related stressors, mindfulness, seven interaction terms for mindfulness, and each work-related stressor as predictor variables. Results revealed that the seven interaction terms were not significant predictors of employee mental or physical health.

\section{Heading level 1:}

Discussion

It is widely recognized that physical and mental health are linked to work-related stressors. Our study offers a valuable novel contribution to understanding these relationships because few previous studies have investigated different domains of work-related stressors in order to compare their relationships with mental and physical health outcomes. The study also adds to the emerging evidence that mindfulness, as a personal resource, has important implications for mental and physical health (Good et al., 2015) and could assist nurses and other healthcare workers in managing the impact of work-related stressors on their well-being.

Comparing scores for the work-related stressors from the current sample to established norms (Edwards et al., 2008), we found that nurses

\section{This article is protected by copyright. All rights reserved}

Commented [MJ2]: $\mathrm{Au}$ : This sentence ("We conducted . . .") was revised. Please verify that your meaning has been preserved. 
and healthcare workers in this sample experienced high levels of job stress, particularly in relation to job demands and job control. Areas such as manager support, peer support, and relationships were also rated below the available norms, indicating that these issues were also a substantial source of work-related stress for the participants in this study. Similarly, mental health scores for our respondents were lower than the established Australian norms (Australian Bureau of Statistics, 1997), whereas physical health scores were within the normal range. Our first hypothesis sought to determine whether, after adjusting for work-related stressors, mindfulness would have a positive relationship with employee mental health. Initially, the results showed that fewer job demands, greater job control, higher levels of peer support, and better relationships at work were positively associated with mental health. After the inclusion of mindfulness, the only work-related stressor that contributed significantly to mental health was job demands. In the final model, higher levels of mindfulness contributed to better mental health, supporting Hypothesis 1. However, fewer job demands also contributed to better mental health, and this is an important finding given the high level of job demands perceived by the nurses and healthcare workers. Nonetheless, the greater contribution of mindfulness to mental health over job demands suggests that it could be beneficial for workplaces to embed mindfulness training into their health promotion activities. This could assist nurses and healthcare workers to build their personal resources, manage work-related stress, and promote employee mental health in general.

Our second hypothesis sought to determine whether, after adjusting for work-related stressors, mindfulness would have a positive relationship with employee physical health. Initially, the results showed that better relationships at work were positively associated with physical health, while none of the other work-related stressors contributed significantly to physical health. In the final model, after the inclusion of mindfulness, the relationships subscale remained significant. While higher levels of mindfulness contributed to better physical health, supporting Hypothesis 2, its contribution to physical health was roughly equivalent to that of relationships at work. Despite the impact of workplace context and mindfulness on physical health, other

\section{This article is protected by copyright. All rights reserved}


aspects of the individual, such as being younger and employed in a nonnursing role, also contributed to better physical health outcomes. While the association between physical health and being younger is not unexpected, the association between job role and physical health raises concerns about the impact of nursing work.

These findings show the value of a multidimensional approach to the measurement of work-related stressors (Bartram et al., 2009; Marcatto et al., 2016), which enables us to establish with greater clarity how workrelated stress affects employee health. This more in-depth understanding can also enable healthcare organizations to target specific work-related stressors in order to reduce the impact of stressful work environments on their employees. By examining the contribution of both work and personal factors, our study has contributed to an understanding of the role of personal resources (Good et al., 2015) and the impact on general health. Workplace context was shown to be important to mental health, but personal resources, in the form of mindfulness, also led to better mental health outcomes. An important contribution of our study is the finding that mindfulness was a substantially stronger predictor of mental health than were work-related stressors. This supports the emerging body of evidence on the value of mindfulness, where mindfulness can play an important positive role in mitigating work-related stressors (Good et al., 2015; Grover et al., 2016). Our results suggest that it is important for nurses and healthcare workers, and their employers, to take a proactive approach to employee well-being to facilitate the capacity for workers to build or restore their personal resources and therefore improve their health outcomes.

\section{Heading level 1:}

Limitations and Future Research

This is a cross-sectional study relying on self-reported measures. To reduce the potential for common-method variance, we followed several recommendations from Podsakoff, Mackenzie, and Podsakoff (2012). The independent variables were presented in different sections of the survey from the dependent variables, response anchors were varied for different scales, and participants were assured of anonymity. While our results are

\section{This article is protected by copyright. All rights reserved}




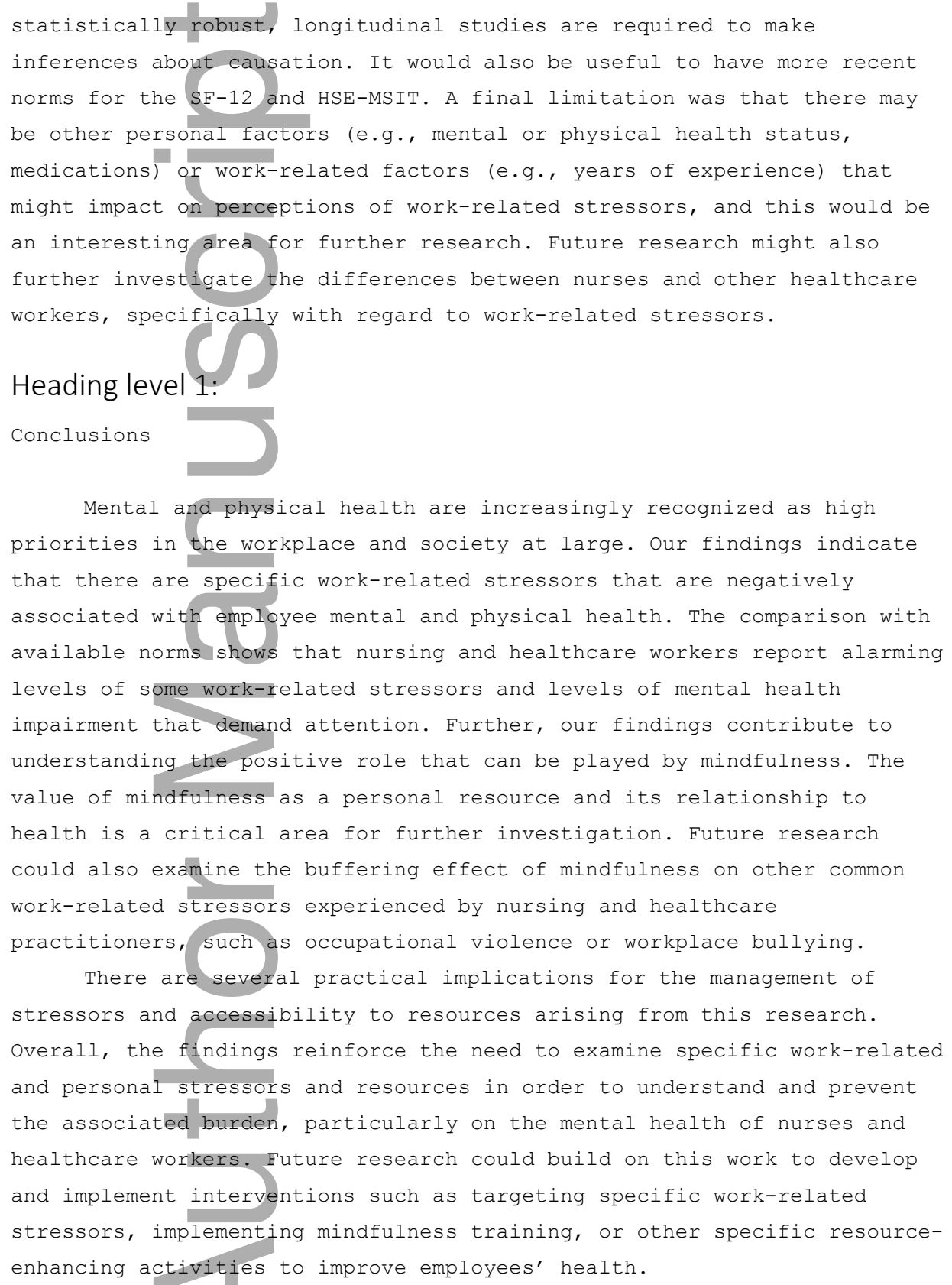

This article is protected by copyright. All rights reserved 


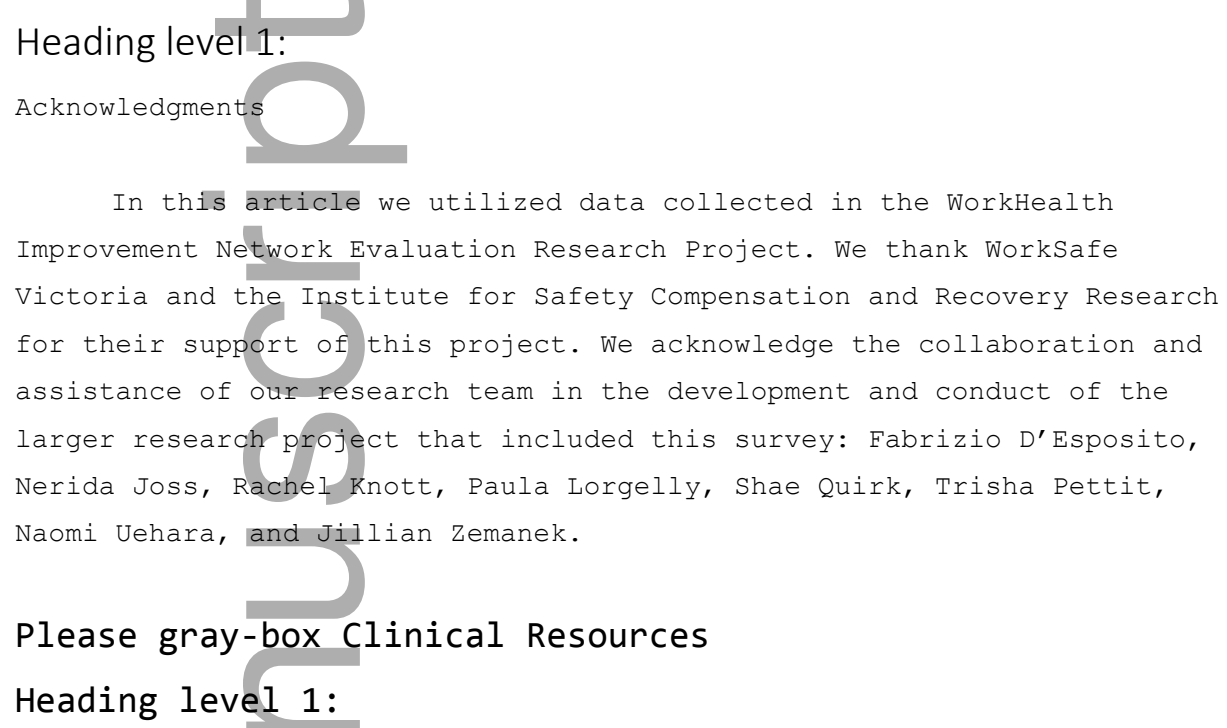

- Royal College of Nursing. Stress and you: A guide for nursing staff. https://www.ren.org.uk/professional-development/publications/pub004967

\section{Heading level 2:}

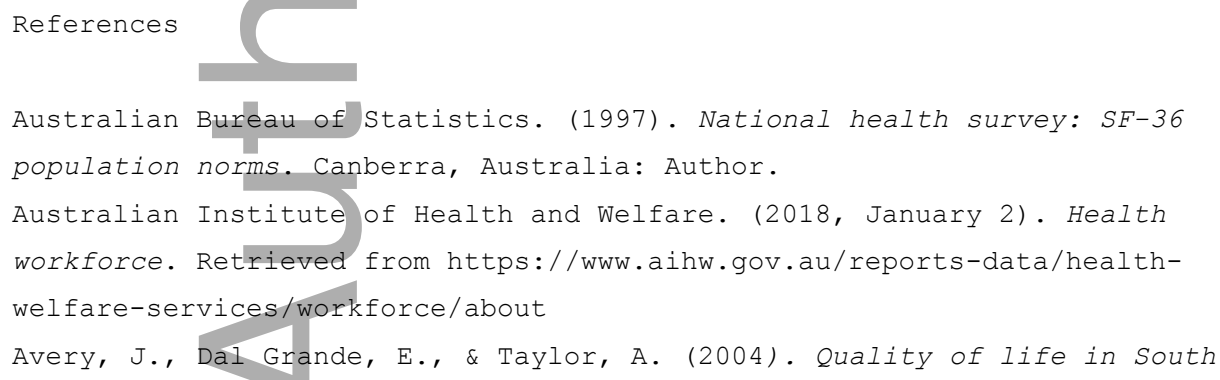

Australian Bureau of Statistics. (1997). National health survey: SF-36 population norms. Canberra, Australia: Author.

Australian Institute of Health and Welfare. (2018, January 2). Health workforce. Retrieved from https://www.aihw.gov.au/reports-data/healthwelfare-services/workforce/about Avery, J., Dal Grande, E., \& Taylor, A. (2004). Quality of life in South

This article is protected by copyright. All rights reserved 
Australia as measured by the SF-12 Health Status Questionnaire: Population norms for 2003: Trends from 1997-2003. Retrieved from http://www.dhs.sa.gov.au/pehs/PROS.html

Bartram, D. J., Yadegarfar, G., \& Baldwin, D. S. (2009). Psychosocial working conditions and work-related stressors among UK veterinary surgeons. Occupational Medicine, 59(5), 334-341.

Cho, H., \& Han, K. (2018). Associations among nursing work environment and health-promoting behaviors of nurses and nursing performance quality: A multilevel modeling approach. Journal of Nursing Scholarship, 50(4), 403-410.

Chu, L.-C. (2017). Impact of providing compassion on job performance and mental health: The moderating effect of interpersonal relationship quality. Journal of Nursing Scholarship, 49(4), 456-465. Cousins, R., Mackay, C. J., Clarke, S. D., Kelly, C., Kelly, P. J., \& McCaig, R. H. (2004). 'Management Standards' work-related stress in the UK: practical development. Work \& Stress, 18(2), 113-136.

Demerouti, E., Bakker, A. B., Nachreiner, F., \& Schaufeli, W. B. (2001). The job demands-resources model of burnout. Journal of Applied Psychology, 86(3), 499-512. Donovan, R. O., Doody, O., \& Lyons, R. (2013). The effect of stress on health and its implications for nursing. British Journal of Nursing, $22(16), 969-970,972-963$.

Edwards, J. A., \& Webster, S. (2012). Psychosocial risk assessment: Measurement invariance of the UK Health and Safety Executive's Management Standards Indicator Tool across public and private sector organizations. Work \& Stress, 26(2), 130-142.

Edwards, J. A., Webster, S., Van Laar, D., \& Easton, S. (2008). Psychometric analysis of the UK Health and Safety Executive's Management Standards work-related stress Indicator Tool. Work \& Stress, 22(2), 96107.

Feldman, G., Hayes, A., Kumar, S., Greeson, J., \& Laurenceau, J.-P. (2007). Mindfulness and emotion regulation: The development and initial validation of the Cognitive and Affective Mindfulness Scale-Revised (CAMS-R). Journal of Psychopathology and Behavioral Assessment, 29(3), $177-190$.

Foureur, M., Besley, K., Burton, G., Yu, N., \& Crisp, J. (2013).

\section{This article is protected by copyright. All rights reserved}




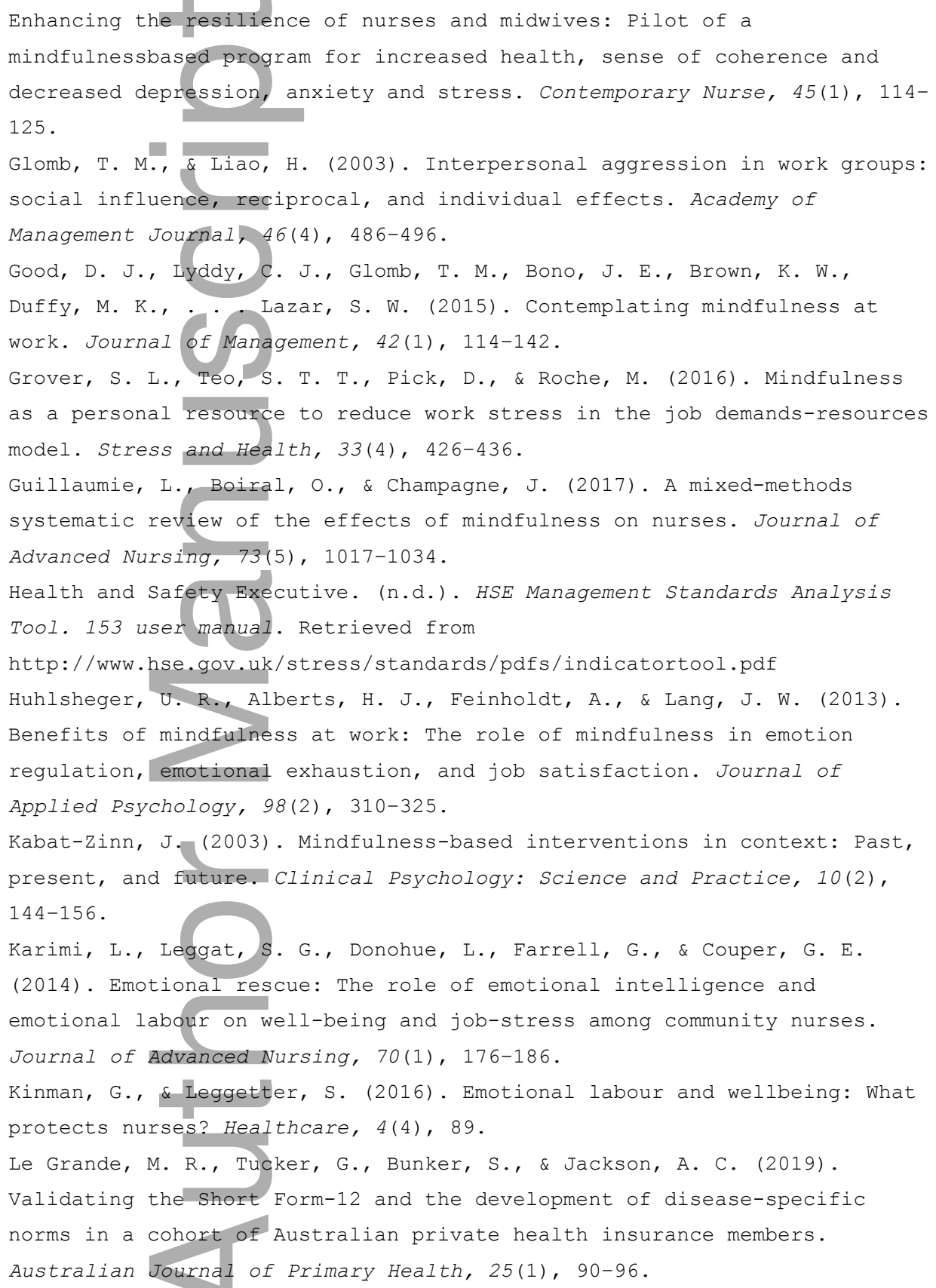

This article is protected by copyright. All rights reserved 
Mackay, C. J., Palferman, D., \& Buckley, P. (2015). Population level interventions to control psychosocial risks: Problems and prospects. In M. Karanika-Murray \& C. Biron (Eds.), Derailed organizational interventions for stress and well-being (pp. 59-70). Dordrecht, the Netherlands: Springer.

Marcatto, F., Colautti, L., Larese Filon, F., Luis, O., Di Blas, L., Cavallero, C., \& Ferrante, D. (2016). Work-related stress risk factors and health outcomes in public sector employees. Safety Science, 89, 274278 .

Maruish, M. E. (2012). User's manual for the SF-12v2 health survey (3rd ed.). Lincoln, RI: QualityMetric Incorporated.

McVicar, A. (2016). Scoping the common antecedents of job stress and job satisfaction for nurses (2000-2013) using the job demands-resources model of stress. Journal of Nursing Management, 24(2), E112-E136.

Perry, L., Xu, X., Duffield, C., Gallagher, R., Nicholls, R., \& Sibbritt, D. (2017). Health, workforce characteristics, quality of life and intention to leave: The 'Fit for the Future' survey of Australian nurses and midwives. Journal of Advanced Nursing, 73(11), 2745-2756.

Podsakoff, P. M., Mackenzie, S. B., \& Podsakoff, N. P. (2012). Sources of method bias in social science research and recommendations on how to control it. Annual Review of Psychology, 63, 539-569.

Reb, J., Narayanan, J., \& Chaturvedi, S. (2014). Leading mindfully: Two studies on the influence of supervisor trait mindfulness on employee well-being and performance. Mindfulness, 5(1), 36-45.

Safe Work Australia. (2018a). Mental health. Retrieved from https://www.safeworkaustralia.gov.au/topic/mental-health\#overview Safe Work Australia. (2018b). Priority industry snapshot: Health care and social assistance. Canberra, Australian Capital Territory, Australia: Author.

Schaufeli, W. B., \& Taris, T. W. (2014). A critical review of the jobdemands-resources model: Implications for improving work and health. In G. F. Bauer \& O. Hämmig (Eds.), Bridging occupational, organizational and public health: A transdisciplinary approach (pp. 43-68). Dordrecht, the Netherlands: Springer.

Schmidt, K. H., \& Diestel, S. (2013). Job demands and personal resources in their relations to indicators of job strain among nurses for older

\section{This article is protected by copyright. All rights reserved}


people. Journal of Advanced Nursing, 69(10), 2185-2195.

Shea, T., Sheehan, C., Donohue, R., Cooper, B., \& De Cieri, H. (2017).

Occupational violence and aggression experienced by nursing and caring

professionals. Journal of Nursing Scholarship, 49(2), 236-243.

van den Tooren, M., \& de Jong, J. (2014). Job demands-resources and employee health and well-being: The moderating role of contract type.

Career Development International, 19(1), 101-122.

van Woerkom, M., Bakker, A. B., \& Nishii, L. H. (2016). Accumulative job demands and support for strength use: Fine-tuning the job demandsresources model using conservation of resources theory. Journal of Applied Psychology, 101(1), 141-150.

Ware, J. E., Kosinski, M., \& Keller, S. D. (1996). A 12-item short-form health survey: Construction of scales and preliminary tests of reliability and validity. Medical Care, 34(3), 220-233.

Westphal, M., Bingisser, M. B., Feng, T., Wall, M., Blakley, E., Bingisser, R., \& Kleim, B. (2015). Protective benefits of mindfulness in emergency room personnel. Journal of Affective Disorders, 175, 79-85.

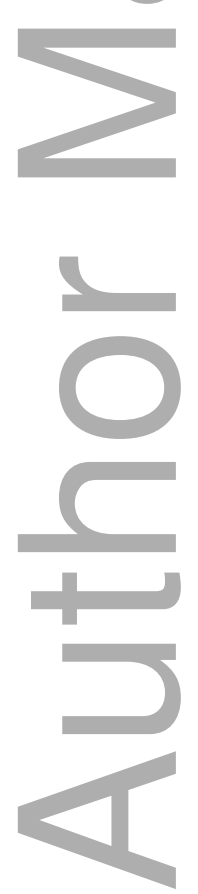

This article is protected by copyright. All rights reserved 
Table 1. Characteristics of the Respondents

\begin{tabular}{|c|c|}
\hline Demographic variable & $\mathrm{N}=702$ \\
\hline \multicolumn{2}{|l|}{ Gender } \\
\hline Male & $106(15 \%)$ \\
\hline Female & $591(85 \%)$ \\
\hline \multicolumn{2}{|l|}{ Age } \\
\hline 18-25 years & $86(12 \%)$ \\
\hline $26-35$ years & $233(33 \%)$ \\
\hline $36-45$ years & $135(19 \%)$ \\
\hline $46-55$ years & $153(22 \%)$ \\
\hline $56+$ years & $92(13 \%)$ \\
\hline \multicolumn{2}{|l|}{ Education } \\
\hline Year 12 or less & $30(4 \%)$ \\
\hline Certificate or diploma & $98(14 \%)$ \\
\hline Tertiary & $572(82 \%)$ \\
\hline \multicolumn{2}{|l|}{ Job role } \\
\hline Nursing employee & $575(82 \%)$ \\
\hline Other healthcare employee & $127(18 \%)$ \\
\hline \multicolumn{2}{|l|}{ Workplace tenure } \\
\hline$<1$ year & $124(18 \%)$ \\
\hline $1-5$ years & $262(37 \%)$ \\
\hline $6-10$ years & $126(18 \%)$ \\
\hline $11-20$ years & $115(16 \%)$ \\
\hline$>20$ years & $74(11 \%)$ \\
\hline \multicolumn{2}{|l|}{ Workplace setting } \\
\hline Aged care & $75(11 \%)$ \\
\hline Community support & $51(7 \%)$ \\
\hline Emergency department & $198(28 \%)$ \\
\hline Intensive care unit & $157(22 \%)$ \\
\hline Maternity & $67(10 \%)$ \\
\hline Perioperative & $67(10 \%)$ \\
\hline Psychiatric & $62(9 \%)$ \\
\hline Other health services & $25(3 \%)$ \\
\hline
\end{tabular}


Table 2. Summary Statistics for Study Variables

\begin{tabular}{|c|c|c|c|c|c|c|c|c|c|c|c|c|c|c|c|}
\hline & $\mathrm{M}$ & SD & Gen & Age & Edu & Job & JD & $\bar{C}$ & MS & PS & Rel & Rol & Cha & Mind & $\mathrm{MH}$ \\
\hline Gender & 1.85 & 0.36 & & & & & & & & & & & & & \\
\hline Age & 2.90 & 1.25 & -.05 & & & & & & & & & & & & \\
\hline Education & 2.77 & 0.51 & -.06 & $-.42^{* * *}$ & & & & & & & & & & & \\
\hline Job role & 0.18 & 0.39 & $-.11^{* * *}$ & .03 & -.00 & & & & & & & & & & \\
\hline Job demands & 2.93 & 0.67 & $-.08^{*}$ & $-.09^{*}$ & -.01 & $.12^{* *}$ & .86 & & & & & & & & \\
\hline Control & 3.01 & 0.71 & -.02 & -.01 & .07 & $.16^{* *}$ & $.38^{* * *}$ & .79 & & & & & & & \\
\hline Manager support & 3.40 & 0.81 & -.01 & $-.11^{* *}$ & .07 & $.07^{*}$ & $.43^{* * *}$ & $.46^{* *}$ & .88 & & & & & & \\
\hline Peer support & 3.67 & 0.68 & .00 & $-.15^{* *}$ & $.18^{* * *}$ & .01 & $.36^{* *}$ & $.41^{* * *}$ & $.64^{* *}$ & .82 & & & & & \\
\hline Relationships & 3.63 & 0.86 & -.04 & $-.16^{* *}$ & $.12^{* *}$ & $.11^{* *}$ & $.46^{* *}$ & $.36^{* *}$ & $.46^{* *}$ & $.53^{* *}$ & .87 & & & & \\
\hline Role & 4.25 & 0.56 & $.08^{*}$ & .06 & -.03 & -.03 & $.18^{* * *}$ & $.25^{* *}$ & $.41^{* * *}$ & $.43^{* *}$ & $.25^{* *}$ & .83 & & & \\
\hline Change & 3.03 & 0.92 & .02 & $-.12^{* *}$ & $.08^{*}$ & .03 & $.36^{* * *}$ & $.39^{* * *}$ & $.59^{* * *}$ & $.47^{* *}$ & $.41^{* *}$ & $.37^{* *}$ & .85 & & \\
\hline Mindfulness & 2.97 & 0.46 & -.02 & $-.12^{* * *}$ & -.03 & .02 & $.16^{* *}$ & $.26^{* *}$ & $.21^{* *}$ & $.21^{* *}$ & $.18^{* *}$ & $.28^{* *}$ & $.18^{* * *}$ & .84 & \\
\hline Mental health & 45.14 & 10.42 & -.02 & $.18^{* * *}$ & -.06 & .01 & $.35^{* *}$ & $.31^{* * *}$ & $.32^{* * *}$ & $.29^{* * *}$ & $.28^{* * *}$ & $.20^{* * *}$ & $.24^{* *}$ & $.53^{* *}$ & \\
\hline Physical health & 52.04 & 7.88 & -.04 & $-.22^{* * *}$ & $.12^{* * *}$ & $.09^{*}$ & $.12^{* *}$ & .03 & .03 & .05 & $.14^{* *}$ & .00 & .02 & $.08^{*}$ & $-.20^{* *}$ \\
\hline
\end{tabular}

Note: Boldface values indicate XXXXXXXXXXXXXXXXXX. C = control; Cha = change; Edu = education; Gen = gender; JD = job demands; Job = job role; $M H=$ mental health; Mind = mindfulness; $M S$ = manager support; PS = peer support; Rel = relationships; Rol = role.

${ }^{*} \mathrm{p}<.05, \stackrel{* *}{\mathrm{p}}<.01$; Cronbach's alpha coefficients are shown on the diagonal where applicable.

This article is protected by copyright. All rights reserved 
Table 3. Hierarchical Linear Regression Results

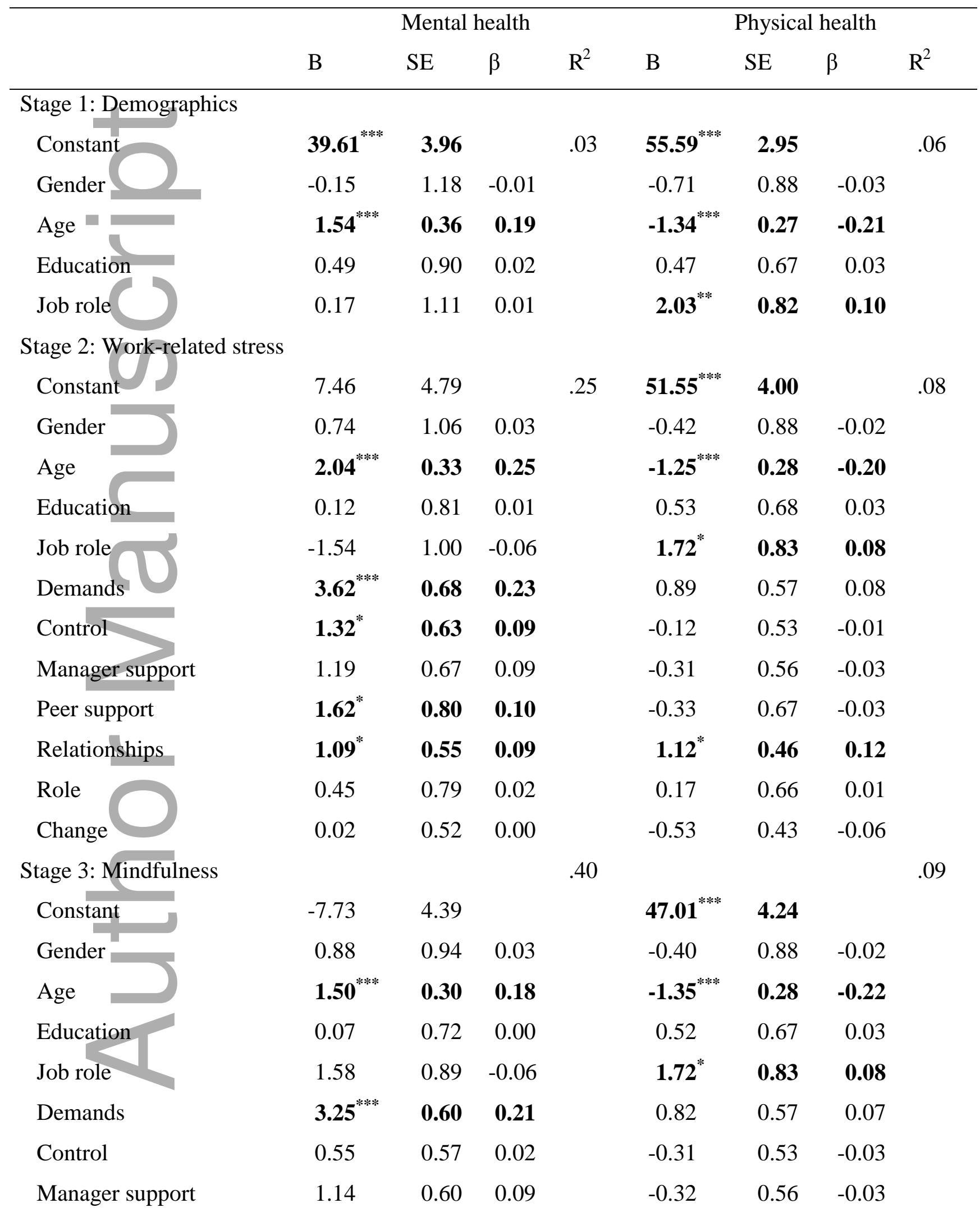

This article is protected by copyright. All rights reserved 


$\begin{array}{lcccccc}\text { Peer support } & 1.30 & 0.71 & 0.08 & -0.39 & 0.66 & -0.03 \\ \text { Relationships } & 0.92 & 0.49 & 0.08 & \mathbf{1 . 0 9}^{*} & \mathbf{0 . 4 6} & \mathbf{0 . 1 2} \\ \text { Role } & -1.20 & 0.71 & -0.06 & -0.14 & 0.67 & -0.01 \\ \text { Change } & 0.05 & 0.46 & 0.00 & -0.53 & 0.43 & -0.06 \\ \text { Mindfulness } & \mathbf{1 0 . 0 0 * * *} & \mathbf{0 . 7 7} & \mathbf{0 . 4 4} & \mathbf{1 . 8 6}^{*} & \mathbf{0 . 7 2} & \mathbf{0 . 1 1}\end{array}$

${ }^{*} \mathrm{p}<.05,{ }^{* * *} \mathrm{p}<.01,{ }^{* * * *} \mathrm{p}<.001 ;$ boldface values denote significant predictors.

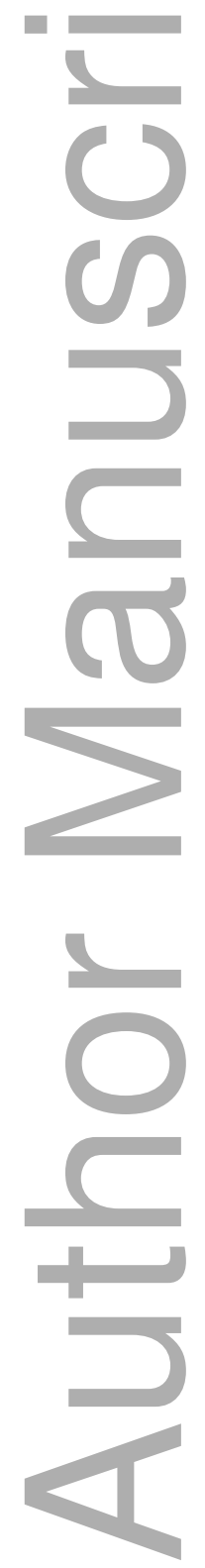

This article is protected by copyright. All rights reserved 


\section{University Library}

\section{- M M N E R VA A gateway to Melbourne's research publications}

Minerva Access is the Institutional Repository of The University of Melbourne

Author/s:

De Cieri, H;Shea, T;Cooper, B;Oldenburg, B

Title:

Effects of Work-Related Stressors and Mindfulness on Mental and Physical Health Among Australian Nurses and Healthcare Workers

Date:

2019-07-21

Citation:

De Cieri, H., Shea, T., Cooper, B. \& Oldenburg, B. (2019). Effects of Work-Related Stressors and Mindfulness on Mental and Physical Health Among Australian Nurses and Healthcare Workers. JOURNAL OF NURSING SCHOLARSHIP, 51 (5), pp.580-589. https:// doi.org/10.1111/jnu. 12502.

Persistent Link:

http://hdl.handle.net/11343/286171 